\title{
LOS DERECHOS SUBJETIVOS Y SU APLICACIÓN EN LA LEY PENITENCIARIA COLOMBIANA *
}

\author{
SUBJECTIVE RIGHTS AND THEIR APPLICATION IN THE COLOMBIAN \\ PENITENTIARY LAW \\ OS DIREITOS SUBJETIVOS E SUA APLICAÇÃO NA LEI PENITENCIÁRIA \\ COLOMBIANA
}

Luz Mireya Mendieta Pineda
Abogada, especialista en instituciones jurídico-políticas.
Magíster en Derecho Procesal de la Universidad Libre. Doctora en Derecho Penitenciario de la Universidad Libre.
Docente-investigadora asociada de la Facultad de Derecho y Ciencias Sociales de la
Universidad Pedagógica y Tecnológica de Colombia, Colombia
luz.mendieta@uptc.edu.co | https://orcid.org/oooo-ooo3-0371-5012

Edward Camilo Ariza Díaz

Estudiante de Derecho de la Facultad de Derecho y Ciencias Sociales de la Universidad Pedagógica y Tecnológica de Colombia. Grupo de investigación Derechos Humanos y Medio Ambiente edward.ariza@uptc.edu.co

\begin{abstract}
Ana Isabel Mendieta Pineda
Abogada, especialista en Derecho Constitucional, en Bioética y en Filosofía de la Ciencia.Magíster en Educación Docente-investigadora del Departamento de Humanidades de la Universidad El Bosque, Colombia mendietaana@unbosque.edu.co | https://orcid.org/oooo-0002-2460-5800
\end{abstract}

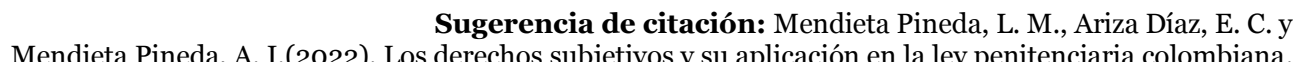

Fecha de recepción: 7 de mayo de 2021

Fecha de aceptación: 15 de septiembre de 2021

Disponible en línea: 12 de octubre de 2021

Mendieta Pineda, A. I.(2022). Los derechos subjetivos y su aplicación en la ley penitenciaria colombiana. Razón Crítica, 12. https://doi.org/10.21789/25007807.1819

\section{Resumen}

Este artículo tiene como propósito dar cuenta de la construcción teórica del concepto de derechos subjetivo y su desarrollo en el derecho penitenciario colombiano. Al respecto, tomaremos como base la pregunta de investigación realizada por el Dr. Gregorio Robles en su libro Teoría del derecho. Fundamentos de teoría comunicacional del derecho (2010): "Cuál crees que es la función de los derechos subjetivos en el derecho penitenciario" (p. 672). La metodología utilizada es documental. Se parte de diferentes conceptos emitidos por algunos teóricos sobre los derechos subjetivos, para luego confrontarlos con la normatividad y con la realidad que viven las personas privadas de la libertad, a partir del análisis de Sentencias de la Corte Constitucional e informes de algunas instituciones. Para concluir, se evidencia la

\footnotetext{
* Artículo de reflexión desarrollado en el contexto del proyecto de investigación denominado "crisis de los derechos humanos en poblaciones vulnerables”, en cooperación con el Grupo de Investigación Derechos humanos y Medio ambiente - reconocido y clasificado en Minciencas 2018 - de la Universidad Pedagógica y Tecnológica de Colombia UPTC; y Grupo de Investigación FHISCIS del Departamento de Humanidades de la Universidad del Bosque, Bogotá .
} 
limitación y la falta de efectividad, en el ejercicio de los derechos subjetivos para las personas privadas de la libertad en centros penitenciarios y carcelarios.

Palabras clave: derechos subjetivos; prisión; cárceles; violaciones de derechos humanos.

\begin{abstract}
The purpose of this article is to provide an account of the theoretical construction of the concept of subjective rights and its development in the Colombian penitentiary law. In this regard, we will take as a basis the research question asked by Dr. Gregorio Robles in his book Teoría del derecho. Fundamentos de teoría comunicacional del derecho (2010): "What do you think is the role of subjective rights in penitentiary law?" (p. 672). Documentary research methodology is used. Different concepts issued by theorists about subjective rights are first described, to be then confronted with the regulations and with the reality that people deprived of liberty live, based on the analysis of Decisions from the Constitutional Court and reports from some institutions. To conclude, the limitation and lack of effectiveness of the exercise of subjective rights for persons deprived of liberty in penitentiary facilities and prisons are evidenced.
\end{abstract}

Keywords: subjective rights; prison; correctional facilities; human rights violations.

\title{
Resumo
}

O objetivo deste artigo é evidenciar a construção teórica do conceito de direito subjetivo e seu desenvolvimento no direito penitenciário colombiano. A respeito disso, tomaremos como base a pergunta de pesquisa realizada por Gregorio Robles no seu livro Teoría del derecho. Fundamentos de teoría comunicacional del derecho (2010): "qual você acredita ser a função dos direitos subjetivos no direito penitenciário” (p. 672). A metodologia utilizada é a documental. Parte-se de diferentes conceitos emitidos por alguns teóricos sobre os direitos subjetivos para, em seguida, confrontá-los com a normatividade e com a realidade que as pessoas privadas da liberdade vivem a partir da análise de Sentenças da Corte Constitucional e dos relatórios de algumas instituições. Para concluir, são evidenciadas a limitação e a falta de efetividade, no exercício dos direitos subjetivos, para as pessoas privadas da liberdade em centros penitenciários e carcerários. humanos.

Palavras-chave: direitos subjetivos; prisão; penitenciária; violação de direitos

\section{Introducción}

En el libro Teoría del derecho. Fundamentos de teoría comunicacional del derecho, del doctor Gregorio Robles (2010), está la pregunta "Cuál crees que es la función de los derechos subjetivos en el derecho penitenciario” (p. 672). A partir de esa pregunta, surge el propósito de tratar de resolverla haciendo un breve comentario sobre el debate teórico de los derechos subjetivos, su evolución y positivización, así como la función que cumplen frente a la persona privada de la libertad y, a la vez, haciendo ver la problemática actual de nuestros centros penitenciarios y carcelarios. 
La metodología utilizada es documental. Se parte de diferentes conceptos emitidos por algunos teóricos sobre los derechos subjetivos, para luego confrontarlos con la normatividad y con la realidad que viven las personas privadas de la libertad, a partir del análisis de sentencias de la Corte Constitucional e informes de algunas instituciones. Para concluir, se evidencia la limitación y la falta de efectividad, en el ejercicio de los derechos subjetivos para las personas privadas de la libertad en centros penitenciarios y carcelarios.

\section{Debate teórico de los derechos subjetivos}

Respecto a los derechos subjetivos, Robles (2010) señala:

Tanto en el derecho privado como en el derecho público los derechos subjetivos aparecen dentro del marco de relaciones jurídicas interpersonales como contenido esencial de dichas relaciones. Estas giran en torno al derecho o derechos subjetivos que conforman el núcleo activo de la relación (p. 602).

Más adelante, el autor señala, respecto al concepto de derechos subjetivos, que es un concepto jurídico que tiene su propia historia, surge en un momento determinado y se desarrolla en el tiempo en medio de los debates de los teóricos. En este sentido, se puede señalar que este concepto responde a procesos de construcción sociales, históricos y culturales que se dan en cada momento, y que se van consolidando o transformando de acuerdo con las diferentes orientaciones teóricas y epistemológicas.

Fernández (1974) dice respecto a los derechos naturales que "son aquellos derechos de los que es titular el hombre no por graciosa concesión de las normas positivas, sino independientemente de ellas y por el mero hecho de ser hombre, de participar de la naturaleza humana" (p. 133). Mientras que Hervada (1991) refiere que "la idea de los derechos naturales es la de unos derechos que, por estar fundados en la dignidad de la persona humana, forman un núcleo objetivo de derechos que no están otorgados por el poder y la sociedad” (p. 350).

Thomas Hobbes, defensor del iusnaturalismo y del iuspositivismo, introdujo la idea de Ius naturale como una potestad enorme, y da a la razón humana un carácter netamente utilitarista. Hobbes (1980) comienza el capítulo 14 de Leviatán dando las definiciones de derecho natural, libertad y ley natural. La ley natural, dice

es un precepto o regla general, descubierto mediante la razón, por el cual a un hombre se le prohíbe hacer aquello que sea destructivo para su vida o elimine los medios para conservarla, así como omitir todo aquello que, en su opinión, puede contribuir mejor a preservarla (pp. 227-228).

Hobbes (1980) emplea la expresión natural rights para referirse a derechos naturales como el significado de derechos subjetivos naturales, es decir, poderes de los que los individuos son titulares por derivar de su propia naturaleza. Para Hobbes, los derechos naturales son los derechos (poderes) que derivan de la propia naturaleza humana, esto es, de la fuerza y de la inteligencia de los individuos, en definitiva: de su poder fáctico (Robles, 2010). 
De conformidad con lo planteado por Hobbes:

los derechos naturales provienen de la propia naturaleza de los hombres, de la naturaleza humana y no de una fuente divina que habría impreso en los hombres unas determinadas características [...]. Los derechos naturales son previos al estado de sociedad civil, por lo cual el estado ha de reconocerlos y garantizarlos (Robles, 2010, p. 612).

Robles (2010) retoma lo expresado por John Locke, al indicar que amplía el concepto de derechos naturales, en el sentido de resaltar la legitimidad del Estado al reconocer a las personas como titulares de derechos naturales como la vida (life), la libertad (freedom) y la propiedad (possessions); mientras que Hart (1955), en su ensayo "¿Existen los derechos naturales?", propone que,

Si de alguna forma existen derechos morales, entonces existe al menos un derecho natural: el derecho de todos los hombres por igual a ser libres. Cuando digo que este derecho existe, quiero decir que, en ausencia de determinadas condiciones especiales consecuentes con el hecho de que el derecho es igual para todos, todo ser humano adulto capaz de elegir: 1) tiene derecho a que los demás se abstengan de ejercer coerción o aplicar restricciones en su contra y, 2) tiene libertad para realizar (es decir, nada lo obliga a abstenerse de realizar) cualquier acto que no sea coercitivo, o restrictivo, o que tenga por finalidad causar daño a otras personas (p. 46).

Ferrajoli (2008), con respecto a los derechos fundamentales, reseña en una de sus obras que,

Son derechos fundamentales todos aquellos derechos subjetivos que corresponden universalmente a "todos" los seres humanos dotados del status de personas, de ciudadanos o personas con capacidad de obrar; entendiendo por "derecho subjetivo" cualquier expectativa (de prestaciones) o negativa (de no sufrir lesiones) adscrita a un sujeto por una norma jurídica; y por "status" la condición de un sujeto, prevista asimismo por una norma jurídica positiva como presupuesto de su idoneidad para ser titular de situaciones jurídicas y/o autor de los actos que son ejercicio de staes (p. 49).

En consecuencia, los derechos subjetivos, naturales, morales, individuales, humanos o fundamentales - como se han llamado en el transcurrir de la historia - no han dejado de ser aquellos derechos que le son inherentes al ser humano y están vinculados a la persona. Por ello, todos los sistemas jurídicos buscan a través de las leyes su protección, por ser derechos innatos, congénitos, inalienables, imprescriptibles, inviolables, intransferibles y exclusivos, que le permiten como persona su goce individual o colectivo.

\section{Algunos momentos de la positivización de los derechos subjetivos}

$\mathrm{Al}$ revisar algunos momentos históricos de positivización de los derechos subjetivos, se podría mencionar como un primer momento de entrada y reconocimiento en la filosofía de carácter iusnaturalista a la Declaración de los Derechos del Buen Pueblo de Virginia (1776), que indica "que los hombres por su naturaleza son igualmente libres y tienen ciertos derechos innatos de los cuales, cuando entran en estado de sociedad, no pueden, por ningún pacto, privar o desposeer a su posterioridad" (Hervada \& Zumaquero, 1992, pp. 26-27). Subsiguientemente, los toma en su terminología la Declaración Francesa de 1789, en los siguientes términos: "los derechos naturales e inalienables del hombre". 
Algunos autores como Peces et al. (1987, p. 98), afirman que estos derechos se vinculan con la idea de constitución y desde entonces no se separan de ella. Posteriormente se da la consolidación de los derechos económicos, sociales y culturales, y se concreta la integración con los derechos civiles y políticos desarrollados en la Constitución de los Estados Unidos de México de 1917, en la Constitución de Weimar de 1919 y la entrada en vigencia de tribunales constitucionales que fueron previstos por Kelsen y recogidos en la Constitución de Austria de 1920; concomitantemente nace el recurso de amparo ante esos tribunales en defensa de los derechos fundamentales (Peces et al., 1987, p. 98).

En textos internacionales, encontramos los derechos subjetivos o naturales incluidos en la Declaración Americana de los Derechos y Deberes del Hombre de 1948, en donde se establece que, "Los estados americanos han reconocido que los derechos esenciales del hombre no nacen del hecho de ser racional de determinado estado, sino que tiene como fundamento los atributos de la persona humana”. En la Declaración Universal de los Derechos Humanos de 1948, al respecto se menciona: “... los pueblos de las Naciones Unidas han reafirmado en la Carta su fe en los derechos fundamentales del hombre, en la dignidad, y el valor de la persona humana y en la igualdad de los derechos del hombre y mujeres; y se han declarado resueltos a promover el progreso social y a elevar el nivel de vida dentro de un concepto más amplio de la libertad".

También se encuentran estos derechos subjetivos en el Convenio Europeo para la Protección de los Derechos Humanos de 1950; en la Convención Internacional sobre la Eliminación de todas las Formas de Discriminación Racial de 1965; en el Estatuto de la Comisión Interamericana de Derechos Humanos de 1965; en el Pacto Internacional de Derechos Económicos, Sociales y Culturales de 1966, y la Convención Americana sobre Derechos Humanos llevada a cabo en San José de Costa Rica en 1969.

Todos los derechos tutelados y consagrados en los documentos internacionales aceptan que se trata de derechos inherentes al hombre, o sea que se reconocen como derechos naturales. Estos derechos, específicamente los llamados "de primera generación" o "derechos civiles o políticos", han sido objeto de reconocimiento a partir del concepto de dignidad humana, del cual se desprenden los demás derechos del ser humano.

En Colombia, los derechos subjetivos están consagrados en nuestra Constitución Política de 1991, así: en el título I - principios fundamentales-, artículo 5, establece que "el Estado reconoce, sin discriminación alguna, la primacía de los derechos inalienables de la persona y ampara a la familia como institución básica de la sociedad"; en el título II -de los derechos, garantías y de los deberes-, en el artículo 11, "el derecho a la vida es inviolable. No habrá pena de muerte"; en el artículo 12, "Nadie será sometido a desaparición forzada, a torturas ni a tratos o penas crueles, inhumanos o degradantes"; en el artículo 13, "Todas las personas nacen libres e iguales ante la ley recibirán la misma protección y trato de las autoridades y gozarán de los mismos derechos, libertades...”, entre otros. 
Los derechos subjetivos son retomados por el Código Penitenciario (Ley 65, 1993) y por el Código Penal (Ley 599, 2000) para que sean tenidos en cuenta, aplicados y no vulnerados por el Estado y sus autoridades, ya sean del orden judicial o del administrativo - como en el caso del INPEC - frente a las personas que afrontan un proceso penal o una sentencia condenatoria.

\section{Función de los derechos subjetivos}

Como lo ha denominado Schneider (1979), la función de los derechos subjetivos "son simultáneamente la conditio sitie qua non ${ }^{1}$ del Estado constitucional democrático, puesto que no pueden dejar de ser pensados sin que peligre la forma de Estado o se transforme radicalmente" (p. 23). Igualmente, agrega que "a estas 'funciones estructurales' de los derechos fundamentales para los principios conformadores de la Constitución se le sigue prestando demasiada poca atención” (Schneider, 1979, p. 23).

Por lo tanto, los derechos fundamentales son representación de un sistema de valores concretos, luego "no existe Estado Constitucional sin derechos fundamentales: estos derechos se convierten en la razón de ser del Estado, cuya función básica es la protección y la efectiva realización de las prerrogativas fundamentales" (Tole, 2004, p. 100). Así, "los derechos fundamentales son la expresión más inmediata de la dignidad humana” (Segado, 1993, p. 207); por lo tanto, operan como derechos de defensa frente al Estado, contribuyendo a salvaguardar la libertad individual.

En el desarrollo jurisprudencial también queda claro que el fundamento de los derechos fundamentales emerge de la dignidad humana en la Sentencia T-095/16 emitida por la Corte Constitucional (2016), posiciones que se comparten y en las que nos apoyaremos para validar la función de los derechos fundamentales de la persona privada de la libertad bajo el régimen del derecho penitenciario.

\section{Derechos fundamentales del privado de la libertad}

La fase de ejecución de la pena empieza con la ejecutoria de la sentencia condenatoria; para el sentenciado inicia con la etapa del cumplimiento de la pena de prisión, impuesta por el juez penal de conocimiento, y su resocialización. Esta fase, que es sumamente compleja porque la persona que ingresa en ella es olvidada por el Estado en relación con las dinámicas internas que se dan en los centros penitenciarios y carcelarios, deja así al privado de la libertad relegado de sus derechos, sobre todo en aquellos que son incólumes e intocables, como es el caso del derecho a la vida y la integridad personal, cuando en cabeza del Estado está la obligación de protegerlos como garante al interior de los establecimientos penitenciarios (Corte Constitucional, Sala Séptima de Revisión de Tutelas, T-276/16, 2016).

En otra sentencia de la Corte Constitucional, se alude que el Estado, desde el momento en que la persona es privada de la libertad, asume la responsabilidad inherente a la seguridad,

\footnotetext{
${ }^{1}$ Condición sin la cual no.
} 
la vida y a la integridad física de los internos (Corte Constitucional, Sala Séptima de Revisión de Tutelas, T-276/16, 2016). Estos aspectos se ven claramente vulnerados con los hechos ocurridos en 13 centros penitenciarios y carcelarios del país el 22 de marzo del 2020, cuando se presentaron enfrentamientos entre los privados de la libertad y la guardia del INPEC, dejando como resultado 23 muertos, 83 heridos y 9 guardianes lesionados en la cárcel Modelo de Bogotá (El Tiempo, 2020, párrafo 4).

La persona privada de la libertad y recluida en centro carcelario o penitenciario, al igual que el resto de los seres humanos, es poseedor de esos derechos subjetivos, individuales y humanos; le pertenecen por ser persona. La Corte Suprema lo ha manifestado cuando afirma lo siguiente: "el Estado está en la obligación de garantizar a los internos el ejercicio de los derechos fundamentales que no han sido suspendidos y parcialmente aquellos que se encuentran limitados, realizando las acciones necesarias para hacer efectivo el goce de los mismos" (Corte Suprema de Justicia, Sala de Casación Penal, Auto N. ${ }^{\circ}$ 3580-2016, radicación N. $\left.{ }^{\circ} 47984,2016\right)$.

Desde sus primeros pronunciamientos, la Corte Constitucional ha insistido en dos aspectos importantes relacionados con los derechos subjetivos del privado de la libertad, por un lado ha indicado que "Ligado al derecho a la vida se encuentra la protección constitucional del valor de la dignidad” (Corte Constitucional, Sala de Revisión N. ${ }^{1}$, T-596/92, 1992), y por otro lado, la importancia de "evitar los sufrimientos innecesarios y los daños irreparables a los internos y a sus familias, pues no solamente excede las finalidades de la pena, sino que también impide la posterior reintegración a la sociedad de la persona privada de la libertad" (Corte Constitucional, Sala Sexta de Revisión de Tutelas, T-265/11, 2011).

$\mathrm{Al}$ respecto, la Corte Constitucional menciona como hechos que ilustra violaciones a los derechos subjetivos en mención, entre ellos: i) usar esposas durante las entrevistas con familiares; ii) practicar requisas degradantes a las personas que van a los establecimientos penitenciarios y carcelarios; iii) prohibir el ingreso el día de visitas a las mujeres en periodo de menstruación (Corte Constitucional, Sala Octava de Revisión, T-690/04, 2004; Corte Constitucional, Sala Segunda de Revisión, T-743/05, 2005; Corte Constitucional, Sala Tercera de Revisión, T-848/05, 2005; Corte Constitucional, Sala Novena de Revisión, T-1062/o6, 2006). Inclusive algunas de ellas son consideradas por el alto tribunal como prácticas inconstitucionales. Se resalta que es importante el acercamiento permanente a la familia porque ello "ayuda a su resocialización” (Corte Constitucional, Sala Séptima de Revisión, T267/15, 2015; Corte Constitucional, Sala Novena de Revisión, T-566/o7, 2007); sin embargo, lo que se percibe es que al Estado no le interesa la suerte del prisionero y de las personas que lo rodean.

En esta misma línea teórica, y que sirve de sustento, están los informes de la Procuraduría, Defensoría, Ministerio de Justicia y del Derecho², Revista Semana 3 , sentencias

2 “... existen situaciones graves y sobrevinientes de orden sanitario que exponen al contagio al personal de los centros de reclusión y que acreditan que las condiciones higiénicas de los mismos no permiten la convivencia en dichos centros de reclusión, que en últimas generan condiciones graves en materia de salud, advirtiéndose, en consecuencia, graves indicios de calamidad pública" el 28 de mayo del (2013) la entonces Ministra de Justicia y 
de tutela de la Corte Constitucional, como la Sentencia T-153 de 19984, la Sentencia T-388 de $2013^{5}$ y la Sentencia T-762 de $2015^{6}$, sentencias que han declarado el estado de cosas inconstitucionales por violación masiva de derechos fundamentales de los privados de la libertad; periódicos como El Tiempo (2018), El Espectador7 (2019) y Redacción Judicial El Espectador (2017; 2018) dan cuenta de las situaciones deplorables de los centros carcelarios y penitenciarios. Además, describen ese otro mundo que se vive en el interior de estos centros relacionados con la corrupción originada en la parte administrativa, la guardia ${ }^{8}$, los mismos reclusos; aunado con el ingreso armas y sustancias alucinógenas con ayuda de las visitas de familiares y amigos, y la colaboración de funcionarios de INPEC. Esto se ve agravado por el hacinamiento carcelario que, según reportes y estadísticas, sobrepasa en Colombia el $55 \%$. Dichos reportes mencionan que:

En 2015 se normalizó la dinámica de entrada y salida de internos, una vez concluida la excarcelación masiva por la aplicación de la Ley 1709 de 2014 y el índice de hacinamiento se regula $54,5 \%$, a partir de entonces se nota una tendencia decreciente confirmada en 2016 (51,2 \%) y 2017 (44,9\%). En 2018 la propensión del hacinamiento es hacia el incremento (44,7\%), continuando así en diciembre de 2019 (54,3 \%); en marzo 2020 (51,2 \%), se observa una disminución de 3,1 puntos porcentuales menos que el último registro (Instituto Nacional Penitenciario y Carcelario [INPEC], 2020, p. 29)

Lo descrito da cuenta de la falta de políticas claras de resocialización ${ }^{9}$ por parte de los Gobiernos de turno, lo que genera un ciclo de violencia a las personas privadas de la libertad,

del Derecho, Ruth Stella Correa Palacio, dio concepto favorable para que la declaratoria de estado de emergencia penitenciaria y carcelaria cobijara todos los centros de reclusión del país" (Corte Constitucional, Sala Séptima de Revisión, T-267/15, 2015).

3 "La situación de las 120.000 personas detenidas en Colombia fue preocupante en 2015 y lo sigue siendo en 2016", dice un informe presentado el pasado jueves 10 de marzo por el Comité Internacional de la Cruz Roja (CICR). "Colombia atraviesa por la peor crisis carcelaria de su historia, problemática que, lejos de superarse, se agudizó en 2015”, afirma la Defensoría del Pueblo en el último informe al Congreso, presentado hace pocas semanas, en el cual llamó fuertemente la atención sobre el tema penitenciario" (Revista Semana, 2016, párrafo 3).

4 "Las cárceles colombianas se caracterizan por el hacinamiento, las graves deficiencias en materia de servicios públicos y asistenciales, el imperio de la violencia, la extorsión y la corrupción, y la carencia de oportunidades y medios para la resocialización de los reclusos" (Corte Constitucional, Sala Tercera de Revisión, T-153/98, 1998). 5 "El hacinamiento penitenciario y carcelario lleva a la escasez de los bienes y servicios más básicos al interior de las cárceles, como un lugar para dormir. Esto lleva a que la corrupción y la necesidad generen un mercado ilegal, alterno, en el cual se negocian esos bienes básicos escasos que el Estado debería garantizar a una persona, especialmente por el hecho de estar privada de la libertad bajo su control y sujeción" (Corte Constitucional, Sala Primera de Revisión, T-388/13, 2013).

6 "Se encuentran afectaciones relacionadas con las condiciones de reclusión a las que, sindicados y condenados, son sometidos: el hacinamiento y las otras causas de violación masiva de derechos, la reclusión conjunta entre condenados y sindicados, las fallas en la prestación de los servicios de salud en el sector penitenciario y carcelario, la precariedad de la alimentación suministrada y las condiciones inhumanas de salubridad e higiene de los establecimientos de reclusión, entre otras" (Corte Constitucional, Sala Quinta de Revisión, T-762/15, 2015).

7 "El Ministerio Público considera que la grave situación de hacinamiento en los centros carcelarios y penitenciarios pone en riesgo los derechos fundamentales" (Redacción Judicial El Espectador, 2017, párrafo 1). "Por lo menos 17 recomendaciones que recibió el Estado colombiano en el Examen Periódico Universal (EPU) en el Consejo de Derechos Humanos de la ONU se referían a adoptar un protocolo especial para revisar la crisis carcelaria. El Gobierno rechazó las propuestas” (Redacción Judicial El Espectador, 2018, párrafo 1).

8 "La corrupción más recurrente y conocida en las prisiones tiene que ver con sobornos de los presos para tener objetos como celulares y armas — por ejemplo, pagan hasta 5 millones de pesos por la más sofisticada en Bellavista-, pero también hay extorsiones de funcionarios del Inpec a los presos. Les piden dinero para incluirlos en las codiciadas listas de quienes pueden redimir pena con trabajo y estudio" (Ortiz, 2019, párrafo 3).

9 "En Colombia, se calcula que el 17,8\% de reclusos son reincidentes; durante los últimos seis años la población reincidente ha aumentado un $47 \%$. Esto indica que los programas de resocialización, precarios y desfinanciados, están cumpliendo una pobre función” (Grupo de prisiones Uniandes, 2019, p. 14). 
ya que el condenado y privado de la libertad es sujeto activo de violación de derechos, pero a su vez es el sujeto pasivo que recibe afectación de sus derechos por parte del Estado. Así se ve reflejado en la realidad que vive Colombia: no hay una búsqueda de opciones, de soluciones a la problemática carcelaria; por el contrario, a nuestros legisladores solo les interesa aumentar las conductas punibles y aumentar los máximos de la pena de prisión ${ }^{10}$ con la convicción errada de que ese aumento va a permitir que no se delinca más y, más grave aún, es la convicción que se tiene por parte de nuestros jueces y fiscales, que creen que solo privando de la libertad y negando la posibilidad de que las personas condenadas sean beneficiados con penas sustitutiva a la prisión o concediendo algún subrogado penal se puede lograr aminorar el sufrimiento que se ha causado a la víctima con el actuar del autor.

No es frecuente que la sociedad y el Estado se detengan a dimensionar el problema carcelario, a establecer si hay o no violación a derechos fundamentales, a fijar las consecuencias del hacinamiento - del cual se habla en la mayoría de informes de derechos humanos sobre de su estado crítico-, de esa situación que puede confirmarse "en el Sexto Informe Periódico al Comité de Derechos Humanos de Naciones Unidas presentado [por Colombia] en diciembre de 2008" (Grupo de Derecho de Interés Público de la Universidad de los Andes en Colombia y la Universidad Internacional de la Florida, 2010, p. 3), como igualmente lo ha reflejado la Corte Constitucional en sus diferentes fallos, como la sentencia T-153/98 de 1998 ${ }^{11}$, en la que se evidencia que las condiciones de salud son deplorables y se ocasiona un sufrimiento físico y mental a la persona recluida, generando la violación a su derecho a la dignidad ${ }^{12}$. Adicionalmente está la violencia física, sexual, el permanente peligro de contagio de enfermedades (Corte Constitucional, Sala Plena, C-248/19, 2019), el problema de la droga, la desnutrición, el trato degradante por parte de la guardia tanto para el preso como para la familia de este, el humillante traslado a los juzgados con las manos esposadas ${ }^{13}$ (Corte Constitucional, Sala Novena de Revisión, T-1030/03, 2003) y sin libertad para caminar.

\footnotetext{
${ }^{10}$ Para ampliar esta información, remítase a la Ley 890 del 2004. Igualmente, el Congreso, desde el 19 de agosto del 2019, estudia por tercera vez la implementación de la cadena perpetua, mediante Proyecto de Acto Legislativo (PAL) N. ${ }^{\circ} 001$ del 2019, el cual tiene por objeto la modificación del artículo 34 de la Constitución Política Colombiana, que aparece en la Gaceta del Congreso con el Número 1084 del 2019.

11 "En un pasillo hay 40 camarotes con capacidad para 40 internos, los internos a su costa construyeron 40 zarzos, ampliando la dormida para 80 personas. Al hacer los zarzos el clima aumentó su temperatura de 25 a 35 o 40 grados en muchas ocasiones, haciéndose insoportable la dormida, pues, por el calor, solo se puede conciliar el sueño después de la media noche y cuando baja un poco la temperatura, pero lo injusto es que no habemos [sic] 80 internos por pasillo, sino que habemos [sic] 170 o 180 personas por pasillo y mientras unos (los de las celdas) nos encontramos durmiendo en baños de sauna, otros sufren la inclemencias del frío, tirados en el pasillo de las celdas y no tienen espacio ni siquiera para poder estirarse y dormir cómodamente" (Corte Constitucional, Sala Tercera de Revisión, T-153/98, 1998).

12 "Las inspecciones le permitieron a la comisión judicial llegar a la conclusión de que las condiciones de reclusión en las dos cárceles citadas son absolutamente infrahumanas, indignas de una persona humana, cualquiera sea su condición personal. Las condiciones de albergue de los internos son motivo de vergüenza para un Estado que proclama su respeto por los derechos de las personas y su compromiso con los marginados" (Corte Constitucional, Sala Tercera de Revisión, T-153/98, 1998).

13 "El empleo de esposas no puede ser considerada la regla general sino la excepción, es decir, cuando circunstancias especiales lo justifiquen en relación con determinado interno, teniendo en cuenta, en concreto, su comportamiento habitual. Mientras que el empleo excepcional de esposas durante los largos trayectos por las instalaciones carcelarias es una medida razonable, debido al comportamiento agresivo y peligroso que ofrezca un determinado interno, y por ende, se pretende evitar graves lesiones al personal de guardia, administrativo, así como a los demás internos, la misma se torna desproporcionada si se aplica de manera indiscriminada y en
} 
La Corte Constitucional ha expresado de manera reiterada que si bien algunos derechos fundamentales de los reclusos son suspendidos o restringidos desde el momento en que estos son sometidos a la detención preventiva o son condenados, muchos otros derechos se conservan intactos y deben ser respetados íntegramente por las autoridades públicas que se encuentran a cargo de los presos. Por ejemplo, los derechos a la libertad física y a la libre locomoción se encuentran suspendidos y, como consecuencia de la pena de prisión, también los derechos políticos.

Derechos como los de la intimidad personal y familiar, reunión, asociación, libre desarrollo de la personalidad y libertad de expresión se encuentran restringidos en razón de las propias condiciones que impone la privación de la libertad. Con todo, otro grupo de derechos, tales como la vida e integridad personal, la dignidad, la igualdad, la libertad religiosa, el derecho al reconocimiento de la personalidad jurídica, a la salud, al debido proceso, y el derecho de petición, mantienen su incolumidad a pesar del encierro a que es sometido su titular $^{14}$.

Los derechos subjetivos de las personas condenadas y privadas de su libertad solo están en el papel. Si bien es cierto que la Ley 599 del 2000 destaca en sus artículos 1 y 4 "dignidad humana" y "funciones de la pena", respectivamente, en concordancia con la Ley 65 de 1993 (Código Penitenciario) con el fin de darle cumplimiento a lo previsto en los artículos 1, 11, 12 y 13 de la carta política, definitivamente no se efectivizan frente a estas personas.

Categóricamente, la vulneración de los derechos humanos de la persona privada de la libertad va en contravía de los tratados y convenios suscritos por Colombia, consagrados para su protección en la Constitución Política (1991), la Ley Penal y Penitenciaria (1993). Las tutelas interpuestas por los mismos internos, que buscan la protección de sus derechos subjetivos, no tienen un valor general: su efecto es a corto plazo y solamente para la persona que la interpone. Luego se ha convertido la tutela en una rueda giratoria, donde se resuelve un problema de manera particular sin que se dé respuesta a una problemática general que afecta a la mayoría de la población privada de la libertad.

La pena privativa de la libertad no es eficaz, así que la pena no aparta al delincuente del delito. Como lo han dichos muchos teóricos, las cárceles son una situación de holocausto, pues es permanente la violación de los derechos fundamentales y hay un constante sufrimiento psicológico para la persona, que lo lleva en muchos casos al camino de la delincuencia.

En este orden de ideas, y con respecto a la pregunta “¿cuál crees que es la función de los derechos subjetivos en el derecho penitenciario?”, se puede indicar que esa función de los derechos subjetivos, de la que tanto se habla y que se ha esbozado en líneas anteriores, no se cumple en la realidad en el derecho penitenciario. Sin embargo, no se desconoce que aquellos

especial en presencia de apoderados y familiares, tanto más y en cuanto estos últimos sean menores de edad" (Corte Constitucional, Sala Novena de Revisión, T-1030/03, 2003).

${ }^{14}$ Sobre el tema de los derechos de los reclusos ver, entre otras, las sentencias: T-424 de 1992, T-522 de 1992, T596 de 1992, T-219 de 1993, T-273 de 1993, T-388 de 1993, T-437 de 1993, T-420 de 1994, T-705 de 1996. 
están positivizados para su protección en la Ley 599 de 2000, en la Ley 65 del 1993 y en la Ley 906 del 2004, pero lo que muestra la realidad a través de diferentes sentencias e informes dados por distintas instituciones - ya referenciadas en el presente texto- es que en temas penitenciarios y carcelarios los derechos subjetivos de la persona privada de la libertad no tienen asidero real y efectivo de protección por parte del Estado.

\section{Conclusiones}

Las disputas en la historia de la humanidad para conquistar el reconocimiento de los derechos subjetivos han respondido a luchas sociales, a procesos de construcción social a lo largo del tiempo y, hoy en día, están plasmados en documentos internacionales y son reconocidos en las constituciones nacionales, lo que genera satisfacción porque el Estado los debe garantizar a todas las personas sin distinción de ninguna clase.

Sin embargo, el desarrollo de la ley penitenciaria, tratándose de los derechos fundamentales y su aplicabilidad en los centros penitenciarios y carcelarios a la población privada de la libertad, muestra la precariedad en la protección real y efectiva de los derechos subjetivos, así como la necesidad de definir políticas fuertes para hacer posible y garantizar su no violación.

Las personas privadas de la libertad seguirán haciendo uso de la acción de tutela como forma de garantía de sus derechos individuales a falta de políticas claras y contundentes sobre protección de derechos fundamentales.

Por último, la función que deben cumplir los derechos fundamentales no se cumple en el sistema penitenciario y carcelario; se requieren cambios trascendentales, sobre todo en la mentalidad del legislador y de los gobernantes de turno, para poderlos garantizar. Mientras ello no ocurra los derechos subjetivos solo quedarán adornando la constitución.

\section{Referencias}

Congreso de Colombia. (1993, 19 de agosto). Por la cual se expide el Código Penitenciario y Carcelario. [Ley 65 de 1993]. DO: 40.999.

https://www.funcionpublica.gov.co/eva/gestornormativo/norma_pdf.php?i=9210

Congreso de Colombia. (2000, 24 de julio). Por la cual se expide el Código Penal. [Ley 599 del 2000]. DO: 44.097.

https://www.funcionpublica.gov.co/eva/gestornormativo/norma.php?i=6388

Congreso de Colombia. (2004, 7 de julio). Por la cual se modifica y adicional el Código Penal. [Ley 890 del 2004]. DO: 45.602.

Congreso de Colombia (2004, $1 .^{\circ}$ de septiembre). Por la cual se expide el Código de Procedimiento Penal. [Ley 906 del 2004]. DO: 45.658. 
Congreso de Colombia. (2014, 20 de enero). Por medio de la cual se reforman algunos artículos de la Ley 65 del 1993, de la Ley 599 de 2000, de la Ley 55 de 1985 y se dictan otras disposiciones. [Ley 1709 del 2014]. DO: 49.039.

Congreso de Colombia. (2019, 31 de octubre). Gaceta del Congreso N. ${ }^{0} 1084$.

Consejo Constitucional. (s. f.). Declaración de los Derechos del Hombre y del Ciudadano de 1789. https://www.conseil-constitutionnel.fr/es/declaracion-de-los-derechosdel-hombre-y-del-ciudadano-de-1789

Constitución Política de Colombia [C. P.]. (1991).

https://www.constitucioncolombia.com/indice.php

Convenio Europeo. (1950). Convenio para la Protección de los Derechos Humanos. Tribunal Europeo de Derechos Humanos [TEDH]. https://www.echr.coe.int/documents/convention_spa.pdf

Corte Constitucional, Sala de Revisión en Asuntos de Tutela. (1992, 24 de junio) Sentencia T-424/92. [MP Fabio Morón].

Corte Constitucional, Sala Cuarta de Revisión. (1992, 19 de septiembre) Sentencia T522/92. [MP Alejandro Martínez].

Corte Constitucional, Sala de Revisión N. ${ }^{0}$ 1. (1992, 10 de diciembre) Sentencia T596/92. [MP Ciro Angarita].

Corte Constitucional, Sala Segunda de Revisión. (1993, 9 de junio) Sentencia T-219/93. [MP Antonio Barrera].

Corte Constitucional, Sala Cuarta de Revisión. (1993, 13 de julio) Sentencia T-273/93. [MP Carlos Gaviria].

Corte Constitucional, Sala Sexta de Revisión. (1993, 15 de septiembre) Sentencia T388/93. [MP Hernando Herrera Vergara].

Corte Constitucional, Sala Cuarta de Revisión de Tutelas. (1993, 12 de octubre) Sentencia T-437/93. [MP Carlos Gaviria].

Corte Constitucional, Sala Tercera de Revisión. (1994, 23 de septiembre) Sentencia T420/94. [MP Eduardo Cifuentes].

Corte Constitucional, Sala Tercera de Revisión. (1996, 9 de diciembre) Sentencia T705/96. [MP Eduardo Cifuentes]. 
Corte Constitucional, Sala Tercera de Revisión. (1998, 28 de abril) Sentencia T-153/98. [MP Eduardo Cifuentes].

Corte Constitucional, Sala Novena de Revisión. (2003, 30 de octubre) Sentencia T1030/03. [MP Clara Vargas].

Corte Constitucional, Sala Octava de Revisión. (2004, 22 de julio) Sentencia T-690/04. [MP Álvaro. Tafur].

Corte Constitucional, Sala Segunda de Revisión. (2005, 14 de julio) Sentencia T743/o5. [MP Alfredo Beltrán].

Corte Constitucional, Sala Tercera de Revisión. (2005, 16 de agosto) Sentencia T848/o5. [MP Manuel Cepeda].

Corte Constitucional, Sala Novena de Revisión. (2006, 7 de diciembre) Sentencia T1062/o6. [MP Clara Vargas].

Corte Constitucional, Sala Novena de Revisión. (2007, 27 de julio) Sentencia T-566/o7. [MP Clara Vargas].

Corte Constitucional, Sala Sexta de Revisión de Tutelas (2011, 7 de abril) Sentencia T265/11. [MP Jorge Pretelt].

Corte Constitucional, Sala Primera de Revisión. (2013, 28 de junio) Sentencia T388/13. [MP María Calle].

Corte Constitucional, Sala Séptima de Revisión. (2015, 8 de mayo) Sentencia T-267/15. [MP Jorge Pretelt].

Corte Constitucional, Sala Quinta de Revisión. (2015, 16 de diciembre) Sentencia T762/15. [MP Gloria Ortiz].

Corte Constitucional, Sala Tercera de Revisión. (2016, 25 de febrero) Sentencia T095/16. [MP Alejandro Linares].

Corte Constitucional, Sala Séptima de Revisión de Tutelas. (2016, 25 de mayo) Sentencia T-276/16. [MP Jorge Pretelt].

Corte Constitucional, Sala Plena. (2019, 5 de junio) Sentencia C-248/19. [MP Cristina Pardo].

Corte Suprema de Justicia, Sala de Casación Penal. (2016, 8 de junio) Auto interlocutorio N. ${ }^{\circ}$ 3580-2016 radicación N. ${ }^{\circ}$ 47984. [MP Fernando Castro]. 
El Espectador. (2019, 20 de agosto). El hacinamiento en cárceles ha sobrepoblado estaciones de policía y URIs, advierten expertos. El Espectador.

https://www.elespectador.com/judicial/el-hacinamiento-en-carceles-ha-sobrepobladoestaciones-de-policia-y-uris-advierten-expertos-article-876909/

El Tiempo. (2018, 4 de octubre). Las cárceles en el país: un eterno problema que tiene solución. El Tiempo. https://www.eltiempo.com/colombia/otras-ciudades/otras-ciudades277268

El Tiempo. (2020, 22 de marzo). Tras enfrentamientos hay 23 muertos y 83 heridos en cárcel La Modelo. El Tiempo. https://www.eltiempo.com/justicia/investigacion/heridos-yfallecidos-tras-amotinamiento-en-carceles-del-pais-475872

Fernández, A. (1974). Derecho natural. Introducción filosófica al derecho. Ceura.

Ferrajoli, L. (2008). Democracia y Garantismo. Trotta.

Grupo de Derecho de Interés Público de la Universidad de los Andes en Colombia y Universidad Internacional de la Florida. (2010). Situación carcelaria en Colombia. https://grupodeprisiones.uniandes.edu.co/images/stories/relatorias/PRISIONESOCT2011/OTRASENTIDADES/OTRASNACIONALES/GDIP/documentotrabajo1.definitivodic11-2012.pdf

Grupo de prisiones Uniandes. (2019). Intervención del Grupo de Prisiones de la Facultad de Derecho de la Universidad de los Andes, en respuesta a la solicitud de la Corte Constitucional.

https://grupodeprisiones.uniandes.edu.co/images/2019/IntervencionCorteConstitucionalECI Final.pdf

Hart, H. (1955). ¿Existen los derechos naturales? The Philosophical Review, 64, 4561. https://www.cepchile.cl/cep/site/docs/20160303/20160303183129/rev37_hart.pdf

Hervada, J. (1991). Los derechos inherentes a la dignidad de la persona humana. Humana Iura I, (1), 345.

Hervada, J., \& Zumaquero, M. (1992). Textos Internacionales de derechos humanos. Universidad de Navarra.

Hobbes, T. (1980). Leviatán. Nacional.

Humanium. (1948). Declaración Universal de Derechos. Humanium. https://www.humanium.org/es/wp-content/uploads/2012/12/Declaraci\%C3 \%B3n-Universalde-Derechos-Humanos.pdf 
Instituto Nacional Penitenciario y Carcelario. (2020, 16 de abril). N. ${ }^{o}$ o3 Informe Estadístico Población Privada de la Libertad. INPEC. https://www.inpec.gov.co/web/guest/estadisticas//document_library/TWBuJQCWH6KV/view_file/1001266?

Organización de los Estados Americanos. (1965). Comisión Interamericana de Derechos Humanos. https://www.cidh.oas.org/annualrep/98span/Capitulo\%201.htm

Organización de los Estados Americanos. (1969). Convención Americana sobre Derechos Humanos. San José, Costa

Rica. https://www.senado.gob.mx/comisiones/desarrollo_social/docs/marco/Convencion_A DH.pdf

Organización de las Naciones Unidas. (1965). Convención Internacional sobre la Eliminación de todas las Formas de Discriminación Racial. https://www.ohchr.org/Documents/ProfessionalInterest/cerd_SP.pdf

Organización de las Naciones Unidas. (1966). Pacto Internacional de Derechos Económicos, Sociales y Culturales. https://www.ohchr.org/Documents/ProfessionalInterest/cescr_SP.pdf\#: :text=Pacto\%20Inte rnacional\%2Ode\%2oDerechos\%20Econ\%C3 \%B3micos\%2C\%20Sociales\%20y\%20Culturales.,1 976 \%2C\%2Ode\%2Oconformidad\%20con\%20el\%20art\%C3 \%ADculo\%2027\%20

Ortiz, M. (2019, 11 de febrero). Escuche los crudos testimonios de la corrupción en las cárceles. El Tiempo. https://www.eltiempo.com/justicia/investigacion/como-se-mueve-lacorrupcion-dentro-de-las-carceles-carceles-presas-de-la-mafia-324666

Peces, G., Hierro L., Iñíguez, S., \& Llamas, A. (1987). Derecho positivo de los derechos humanos. Debate.

Redacción Judicial El Espectador. (2017, 8 de junio). Procuraduría pide acciones para evitar "tratos inhumanos y degradantes" a los presos. El Espectador. https://www.elespectador.com/noticias/judicial/procuraduria-pide-acciones-para-evitartratos-inhumanos-y-degradantes-a-los-presos/

Redacción Judicial El Espectador. (2018, 14 de mayo). Colombia se niega a que la ONU examine la situación en las cárceles. El Espectador.

https://www.elespectador.com/noticias/judicial/procuraduria-pide-acciones-para-evitartratos-inhumanos-y-degradantes-a-los-presos/

Revista Semana. (2016, 18 de marzo). Tres razones para una inminente tragedia en las cárceles. Revista Semana. https://www.semana.com/nacion/articulo/carceles-en-colombiauna-tragedia-inminente/465969/ 
Robles, G. (2010). Teoría del derecho: fundamentos de teoría comunicacional del derecho. Aranzi.

Schneider, H. (1979). Peculiaridad y función de los derechos fundamentales en el Estado constitucional democrático. Estudios políticos, (7), 7-36. https://dialnet.unirioja.es/servlet/articulo?codigo $=1427304$

Segado, F. (1993). La teoría jurídica de los derechos fundamentales en la doctrina constitucional. Derecho constitucional, (39), 195-247. https://dialnet.unirioja.es/descarga/articulo/79497.pdf

Tole, J. (2004). La teoría de la doble dimensión de los derechos fundamentales en Colombia. El estado de cosas inconstitucionales, un ejemplo de su aplicación. Derecho del Estado, (16), 99-143. https://dialnet.unirioja.es/descarga/articulo/5119715.pdf 